to haemodynamic crises. Hyperkalaemia has been amply documented in the past because it was searched for. The other events (e.g., massive response of the sympathetic system or an absence of the sympathetic response) may be demonstrated if deliberate attempts are made in the future to document it. The development of malignant hyperpyrexia is a relatively late event after the administration of SCh and therefore goes beyond the confines of the hypothesis.

Some of the suggestions proposed by Dr. Baraka fall well within the frames of the hypothesis and are discussed there. The other proposals appear unlikely.

Again, I thank Dr. Baraka for his comments.

Vladimir Nigrovic MD

Departments of Anesthesiology and Pharmacology Medical College of Ohio

Toledo, Ohio 43699 U.S.A.

\section{Single segment combined subarachnoid and epidural block for Caesarean section}

To the Editor:

Epidural and subarachnoid blocks are well-established methods of regional anaesthesia for Caesarean section. However, these techniques have certain drawbacks. Both techniques are associated with a relatively high risk of maternal hypotension which may be precipitous following subarachnoid block and can lead to neonatal depression. ${ }^{1-4}$ Difficulty in controlling segmental spread of analgesia may be another disadvantage of subarachnoid block. Also, due to requirement of large doses of local anaesthetics for epidural block there is a risk of toxic complications. ${ }^{5,6}$ Furthermore, in spite of large doses epidural block may fail to provide adequate analgesia in up to 25 per cent of patients due to difficulty in blocking sacral roots. ${ }^{37-9} \mathrm{~A}$ technique is described which combines the reliability of subarachnoid block and the flexibility of epidural block while minimizing or eliminating their drawbacks.

Twenty-four healthy patients scheduled for elective Caesarean section were included in the study after obtaining their informed consent. Before induction of combined subarachnoid and epidural (CSE) block about $1500 \mathrm{ml}$ of fluids warmed to $37^{\circ} \mathrm{C}$ by a blood warmer were administered IV over

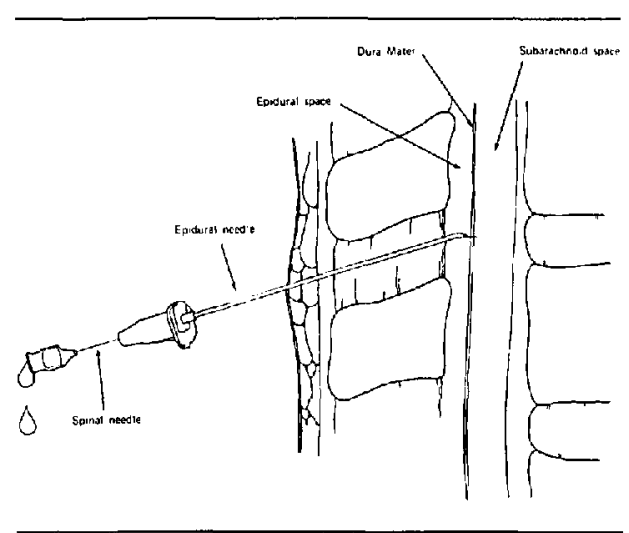

FIGURE Twenty-seven gauge spinal anesthesia needle inserted through a 16 gauge Tuony needle previously placed in epidural space.

a period of $15-20 \mathrm{~min}$. With the patient in the sitting position a $16 \mathrm{G}$ Tuohy needle was inserted at the L2-3 interspace and the epidural space identified. A long 26 or $27 \mathrm{G}$ spinal needle was introduced through the caudad directed Tuohy needle and the dura penetrated. After correct placement of the spinal needle was confirmed $1.5-2.0 \mathrm{ml}$ of 0.5 per cent hyperbaric bupivacaine (depending on the height of the patient) were injected into the spinal needle which was then withdrawn (Figure). The Tuohy needle was rotated $180^{\circ}$ cephalad and a catheter introduced into the epidural space. After securing the catheter firmly by tape the patient was placed in the supine position with left uterine displacement and the head of the operating table elevated $10-15^{\circ}$.

After the spinal block was "fixed" (about 15 min) and extent of analgesia noted the block was extended to the T4 dermatome by injecting fractionated doses of $5 \mathrm{ml} 0.5$ per cent bupivacaine in the epidural catheter. The epidural catheter was also used to provide postoperative analgesia on demand by administration of $4 \mathrm{mg}$ morphine. Early ambulation was encouraged following regression of CSE block. Following surgery $10 \mathrm{ml}$ of saline was injected every four hours in the epidural catheter. The epidural catheter was removed after 48 hours.

The mean dose of 0.5 per cent hyperbaric bupivacaine given for subarachnoid block was $1.7 \pm 0.2 \mathrm{ml} \mathrm{S}$.E.M. (range $1.5-2.0 \mathrm{ml}$ ) and the 
mean total dose of 0.5 per cent bupivacaine injected epidurally was $8.1 \pm 0.26 \mathrm{ml}$ (range $5-10 \mathrm{ml}$ ). The subarachnoid block usually extended from S5 to T7 dermatomes. The usual upper level of the CSE block after injection of local anaesthetic via the epidural catheter was T4. In six patients (25 per cent) the subarachnoid block reached the T4-5 level and further extension of block by epidural injection of local anaesthetic was not required. All patients had good to excellent surgical analgesia. Similar assessment was made by the obstetric surgeon and the nurse anaesthetist. During surgery supplemental analgesics were not required in any patient. However, three patients (13 per cent) complained of nausea following manipulation of the peritoneum, and this was treated by an antiemetic.

In this study hypotension (defined as a 30 per cent fall in blood pressure compared to preoperative values or a systolic blood pressure below $100 \mathrm{mmHg}$ ) was uncommon (13 per cent) following subarachnoid block. When the CSE block was extended to the $\mathrm{T} 4$ dermatome by epidural injection of bupivacaine four patients ( 17 per cent) developed hypotension. However, the occurrence of this complication was considerably less frequent and less severe than that reported for epidural or subarachnoid block alone. ${ }^{1-4}$ Although the number of patients is too small to draw definite conclusions none of the 24 parturients developed postspinal headache in spite of early postoperative ambulation due to effective pain relief.

The advantages of CSE block over epidural block for Caesarean delivery are: minimal risk of maternal toxic reaction due to requirement of considerably smaller doses of local anaesthesia drug, more reliable block and less risk of maternal hypotension. As compared to subarachnoid block the advantages of CSE block are: possibility of extending an inadequate block, possibility of providing postoperative analgesia by local anaesthetics or opioids, less risk of severe maternal hypotension and apparent absence of postdural puncture headache if opioids are administered epidurally. Controlled studies are necessary to evaluate the technique further.

\section{Narinder Rawal MD PH D}

Department of Anesthesiology and Intensive Care Örebro Medical Center Hospital

Örebro, Sweden

\section{REFERENCES}

1 Datta S, Alper MH. Anesthesia for cesarean section. Anesthesiology 1980; 53: 142-60.

2 Clark RB, Thompson DS, Thompson CH. Prevention of spinal hypotension associated with Cesarean section. Anesthesiology 1976; 45: 670-4.

3 Larsen JV. Obstetric analgesia and anaesthesia. Clinics in Obst Gyn 1982; 9: 685-710.

4 Gibbs CP, Werba JV, Banner TE, James CF, Hill $C R$. Epidural anesthesia: leg-wrapping prevents hypotension. Anesthesiology 1983; 59: A405.

5 Abouleish E, Bourke D. Concerning the use and abuse of test doses for epidural anesthesia. Anesthesiology 1984; 61: 344-5.

6 Thorburn J, Moir DD. Bupivacaine toxicity in association with extradural analgesia for Caesarean section. Br J Anaesth 1984; 56: 551-3.

7 Thorburn J, Moir DD. Epidural analgesia for elective Caesarean section. Technique and its assessment. Anaesthesia 1980; 35: 3-6.

8 Kileff ME, James FM, Dewan DM, Floyd HM. Neonatal neurobehavioral responses after epidural anesthesia for Cesarean section using lidocaine and bupivacaine. Anesth Analg 1984; 63: 413-7.

9 Morgan BM, Aulakh JM, Barker JP, Goroszeniuk T, Trojanowski A. Anaesthesia for Caesarian section. Br J Anaesth 1983; 55: 885-9.

\section{Late venous perforations due to percutaneous central venous cannulation}

To the Editor:

In reference to the case report of Naguib et al. describing bilateral hydrothorax and hydromediastinum after subclavian line insertion, ', we would like to report our experience with similar complications after central vein catheterization with inflexible left-sided lines.

We encountered no cases of pleural effusion following right-sided insertion of 750 polyethylene catheters (18 cm long, $1.5-2 \mathrm{~mm}$ diameter Leadercath VYGON@ or $20 \mathrm{~cm}$ long, $2 \mathrm{~mm}$ diameter - Seldiflex Plastimed(\&) by the Seldinger technique. In contrast, following placement of 450 catheters via the left internal jugular vein or the left 